\title{
New Media Usage among School Children of Bangalore
}

\author{
Suparna Naresh ${ }^{*}$
}

\section{Abstract}

A study conducted by the Kaiser Family Foundation in the United States during the turn of the millennium showed that children in America spent almost five hours watching television and two hours in front of the computer. As recently as June 2010, the World Summit on Media for Children and Youth held in Karlstad, Sweden held sway on the topic- 'Towards the new global vision for children, youth and media'. Alberto Pellai, the Summit keynote speaker (representing the department of Public Health at the University Degli Studi Di Milano, Italy) touched upon the need for media education emphasizing on media content that had to educate and help in the growth and development of children rather than mislead the beliefs and value system of children. Statistics reveal new media as being a strong contender for top spot of favoured past time among children. It no longer surprises people that the time spent by children on new media usage has tripled in the last ten years in the US (Kaiser Family Foundation report). Children in urban India from all accounts are no different from their American counterparts. This trend needs to be pondered, debated and questioned. The researcher would like to explore the different issues related to children and new media usage from an urban perspective since new media is more accessible to urban Indians for obvious reasons- finance,

* Associate Professor, Department of Media Studies, Christ University, Bangalore, India; suparna.naresh@chrituniversity.in 
socio-cultural readiness towards new, innovative medium of communication (new media) and educational background. Through interactive sessions with school students, parents and teachers the researcher would like to find out- why children use new media, the content used by children, parent perception of new media usage by their children, teacher's view on new media usage by students. According to Bagman, a popular blogger, there are two kinds of people, "Whenever there is a question of a new medium, there are those who are excited because of it and those who are wary of it." The researcher too, through this paper, would like to know which way people in urban India are inclined.

Keywords: Internet, ICT, New media, Social media

\section{Introduction}

A study on the way internet is perceived by children between the ages 9-15 of Bangalore city and other related issues concerning the subject of ICT and development.

The general perception or notion regarding new media is one of ready acceptance of it by most urban users and it being a cure for almost all of the modern day ills of the society. Truth be told, not many of us have really tried to find out the efficacy of such a notion. Whatever be the case, one needs to explore and perhaps question the presence of this new technology that has most certainly taken a stronghold of our lives. To quote Lucy King, author, "The internet has established itself with remarkable, perhaps unprecedented speed as an integral part of everyday life for many people all over the world, at work and in the home."

According to most pro-technology thinkers, technology is perhaps the most prominent, ready-made instant solution, that can miraculously overcome resource constraints, generate growth, lead to development and be the proverbial and ultimate problem-solver. In recent times this belief of 'technology being the panacea as it were' has limited takers. Be it the academician, sociologist or the overprotective parent, people are beginning to question- Is this a good trend? One can't say conclusively. 
Many people are of the opinion that the growth spurt of ICT should be allowed because the positive of this far outweighs the negative. According to Ashwani Saith and Vijay Bhaskar (authors, ICT and Indian Social Change), "Who would wish to challenge the power of technological change? It cannot be gainsaid that technological change has been a primary driver and generator of long-term growth and structural change for the past two centuries. But equally, the stoical peasant or the emaciated rural labourer as the intended beneficiaries of the green, white or bio-genetic revolution or the daily threatened migrant slum-dweller, living under the motorway arch or in the shadow of urban skyscrapers, might wish to testify that somehow such technology driven growth seems to have passed them by. Far from technical change being a problemsolver, their perception might often be that of it being a problem creator."

Presently there is this constant tussle between the pro-technology and the not-so-pro technology thinkers, termed as the divide between technological optimism and technological reductionism. The emphasis today is not so much on technology as a quick-fire approach but rather on user based initiatives that make technology more socially relevant and responsive. Technological changes are often seen as beneficial, exciting, interesting and confusing - all in one go. The dimension to these changes has to be seen from different angles - economic, political and social. The changes affect the society significantly and can be seen influencing media, consumers and producers, users and non-users. It is in this context that a study on the internet and its impact on young users become relevant. This paper seeks to relate issues concerning children and the ever growing popularity of internet in their lives.

The internet refers to a telephony-based system that links computers and computer networks worldwide to permit distribution of data, e-mail messages and visual and audio materials to individuals, groups of individuals and the public. Today more than anything else the internet is seen as one allpervasive medium which surrounds us 24/7. Since the data transmitted through the Internet and other distribution systems include telephones, television, radio and computers, its impact is that much wider. 
Researcher Ruth Towse, Professor, University of Rotterdam, the Netherlands and Bournemouth University, UK has this to say about this interest by academicians in trying to understand the power and impact of the internet- "Research is being done in the field of media industries by people who specialize in a range of disciplines - media and business, economics, communications, cultural economics, cultural studies, media management, media technology, political science and sociology - who share an interest in the impact of the Internet. This interest is both 'academic', in the sense that we want to know the what, why, and how of its impact, but we also share a concern to provide a basis from which to objectively assess policy. Each of the disciplines represented by the researchers who have contributed to a better understanding of the problem at hand and offer a different perspective. This is important as there has been inordinate hype and over-excitement about the power of the Internet and related technologies.

A point that needs to be emphasized is, since the Internet is not owned or regulated by a recognized body or authority there is no single responsible body that is in a position to provide information about it. In recent years efforts have been made to change this scenario. Public and private organizations collect Internet data for a range of purposes, governments collect statistics on 'connectivity' to monitor their IT policies, international data is collected for the purpose of trade and so on. With Internet usage reaching 467 million in Asia alone (of which India has 60 million users), it is imperative that a better understanding of the same be had.

Some interesting work on Children and Internet has been done by the J. Kaiser foundation, USA - from the 'patterns of Internet usage' to 'violent content on the internet and children'. Researcher Rebecca Clay of the American Psychological Association in her study "Unraveling new media's effects on Children" says this "Consuming media it seems, has far outstripped reading story books or playing dress-up, as the average American child's favourite pastime. Overall children between the ages of two and eighteen spend an average of almost five-and-a-half hours a day at home watching TV or surfing the web. Thanks to pressure from APA and other researchers, grants are being given to study how 
interactive media (Internet based) affect children's learning, social skills and identity issues."

An average teen, be it in India or elsewhere, is surrounded by technology the moment they wake up to a new day. Andrea Press, researcher has this to say about media and children. "My 15 year old daughter gets up in the morning and turns on her computer and radio at the same time - while text messaging her friends before school, she downloads new songs to her MP3 player. When she comes home and turns to homework it is done on the computer while she keeps track of her friends on the social networking site Facebook."

This is not an isolated example of a family's habits but quite a common scene across the globe. The experience of living between media use is a universal phenomenon almost in both developed and developing worlds, crossing cultural, social class and racial lines. As the media environment changes around us, so too our lives, which is so tightly interwoven with media. As Marshall McLuhan said- "Change in broader communication cultures alter the very structure of human consciousness." (1964)

\section{Methodology}

Towards this end of trying to uncover issues related to Internet usage by school children, the present study has been conducted to get a clearer picture closer home. A sample of fifty students was chosen through convenience sampling, between the ages 9 to 15 including male and female respondents. A questionnaire was administered. For the sake of convenience only close ended questions were chosen. Further, in-depth interviews of three parents and three teachers were conducted to get their opinion on the said topic.

\section{Analysis and findings}

When it comes to the impact of media - traditional or new - there is an assumption that it will lead to certain specific, expected changes in our lives called 'technological determinism', this has much to answer for as regards to one's understanding of media 
influence/impact. Studies, however small or big help in controlling the build-up of such pre-conceived notions or assumptions.

Given below is the questionnaire that was administered to the students.

1. Which is the most preferred medium? TV, Radio, Newspapers, Internet or Books

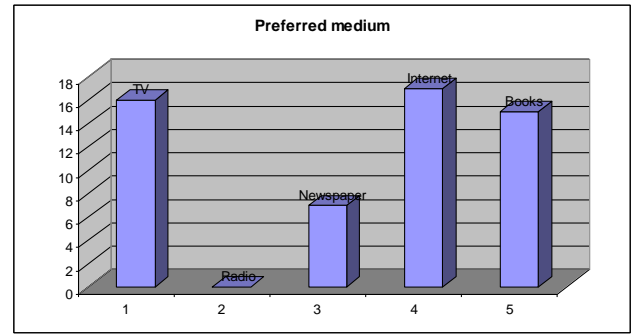

As is clear from the table, first preference is Internet followed by TV, Books, and Newspaper and interestingly Radio has none. According to a study/ research conducted in Spain (Civertice, 2006) boys and girls between the ages 10 and 18 prefer the most interactive medium, if they have to choose among TV and the Internet, 38 percent of them prefer Internet over the 30 percent that choose TV.

Further proof of the popularity of the Internet with children is seen in the study 'UK Children Go Online' (Livingstone \& Baker, 2005) where 25 percent of the children interviewed had sent a message to the website when it came to their responses.

\section{How often do you use the internet in a day?}

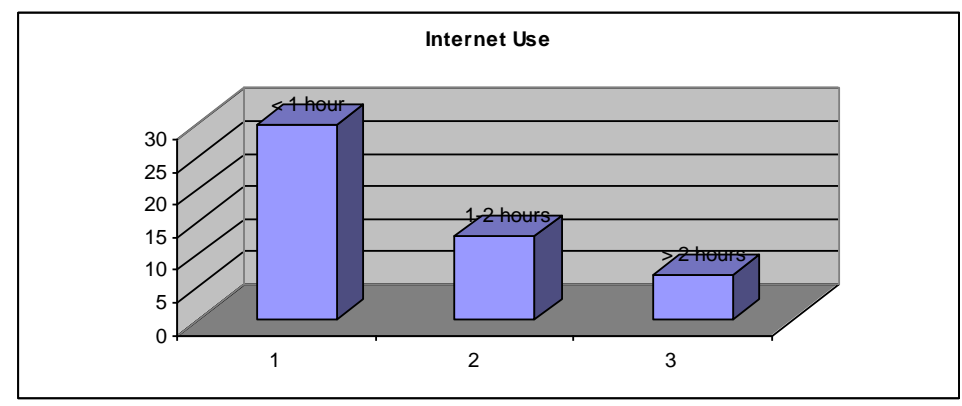


The majority of the students spend less than one hour per day on the Internet, a small number between 1-2 hours and even smaller number more than 2 hours per day.

In the study, UK Children Go Online (Livingstone \& Baker, 2005) it is reported that younger children, though they use Internet, use it for less than an hour, whereas, the older the children get, the time spent on the net increases. The same trend is seen here too younger ones use it less than their older counterparts.

\section{Why do you use the internet?}

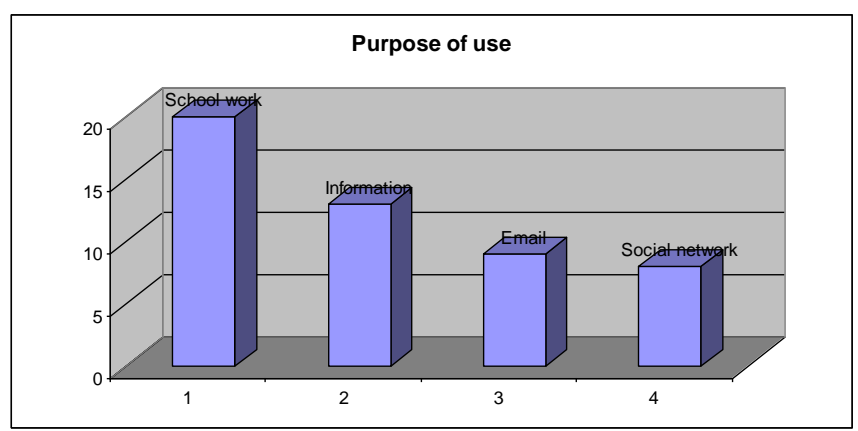

Majority of the respondents use the Internet for school work. Information or general knowledge gets the second preference. Email/chat comes third with social networking coming in last. Not surprising since the respondents are young kids with little exposure to social networking.

\section{Is there adult supervision when using the internet?}

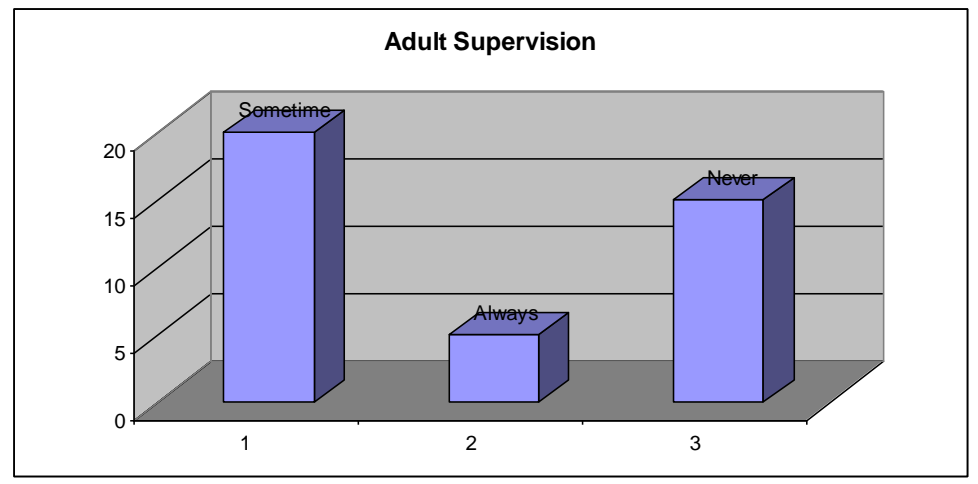


When the question of supervision and Internet usage is raised we see the choices 'sometimes' and 'never' are more or less equally pitted. It shows that while some parents are okay with their children using Internet on their own, there are still those who would like their kids to have supervised Internet usage.

\section{Has internet usage affected the following things?}

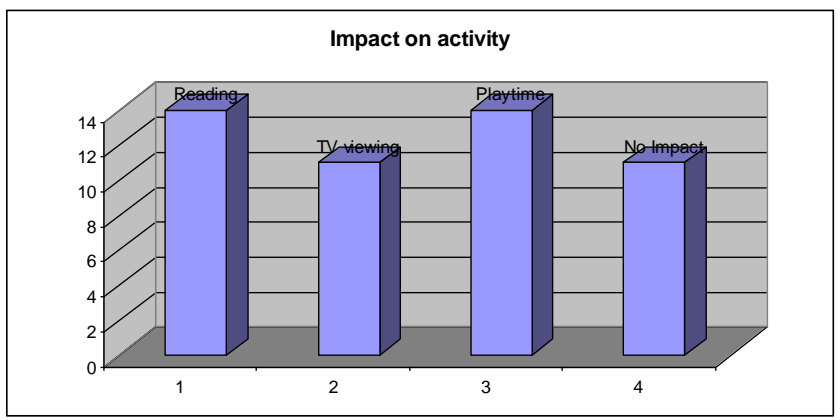

It is an accepted fact that many technologies have been short lived or complete failures (Pagers) while other technologies have been adopted whole heartedly. According to Piet Bakker and Charo Sadaha (Impact of the Internet on Users, 2005), "Internet users are in many cases active, looking for those pieces of content to satisfy their particular and concrete needs... Internet exceeds the idea of a medium as an information or entertainment container. It is a strong personal communication vehicle and a social platform as well." With Internet gaining popularity with the children, other media usage by children has definitely suffered, as it can be clearly seen in the present study. Reading and playtime has suffered equally, with TV coming a close third. There is still a small minority that says Internet usage has not affected other activities. Being children it may be possible that they are not the best judge of 'effects' in the first place. Kaye and Johnson (2003) concluded that both TV and radio suffered due to the pervasiveness of Internet in the US. "The trend indicates that those Internet users whose media pattern has changed are abandoning traditional media at a much greater rate than they are increasing their use".

In October 2006, research carried out among 5000 people by Jupiter Research in the five biggest European markets (UK, France, 
Germany, Spain and Italy) revealed that time spent online, had overtaken time spent on newspapers and other mediums.

\section{Are your parents ok with you using the internet?}

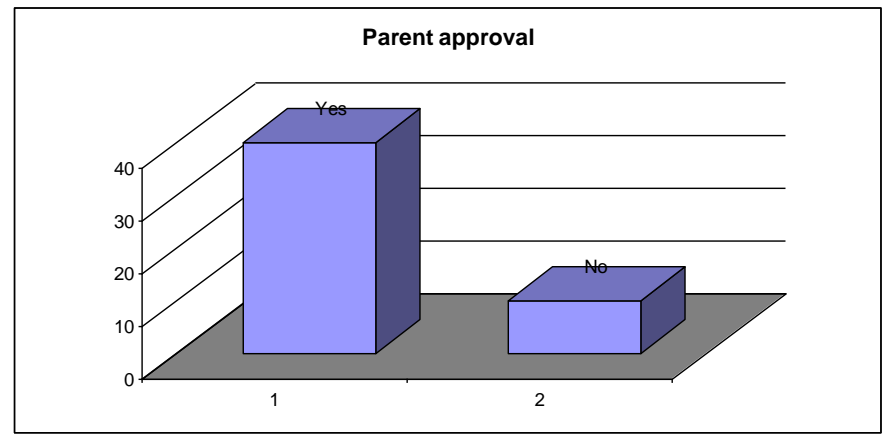

As can be seen from this table, more than 80 percent of the children questioned say that they have their parent's approval for using the Internet. With a small 20 percent saying they do not have the approval. This trend should, by right, be a cause for concern. Parents are seen readily accepting Internet as a fact of their children's lives. Parents should be more skeptical of the internet and its effect. Many academicians feel that this may be due to the status attached to anything related to computers in India, since computers and related subjects are generally viewed with ready acceptance.

\section{Do your teachers encourage you to use the internet for school work?}

Out of fifty respondents, thirty say teachers encourage the students to use Internet and twenty say their teachers don't. This comes as no surprise since Internet and Internet based media are unequivocally allowed in many educational institutions; if not in class the students are encouraged to use the same at home for their curricular work. 


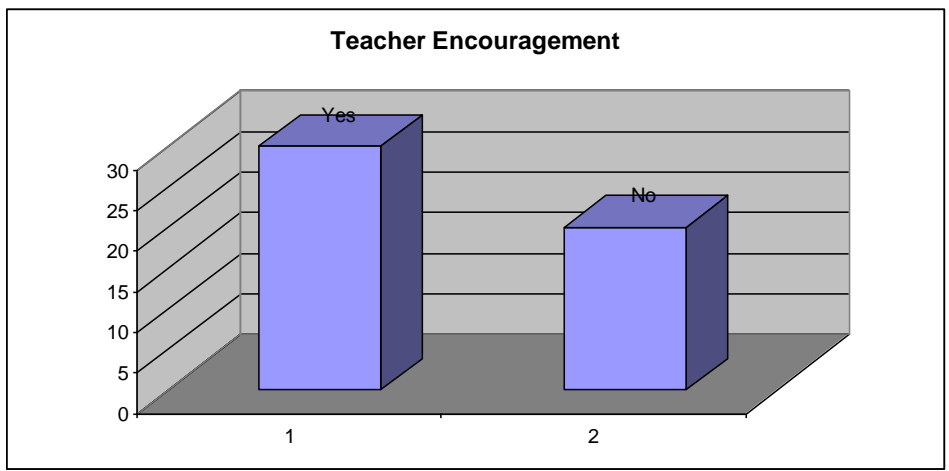

The modern classroom has changed - From schools to university lecture halls, media is ubiquitous. In lectures, professors often have a computer hooked up to the Internet. In most city schools in India, classrooms have projectors making internet connectivity possible if needed. To quote Andrea Press, "While once controversial when used in an educational setting, the current widespread acceptance of media as an integral part of the educational process, has influence far beyond the classroom."

\section{How has internet usage affected your grades?}

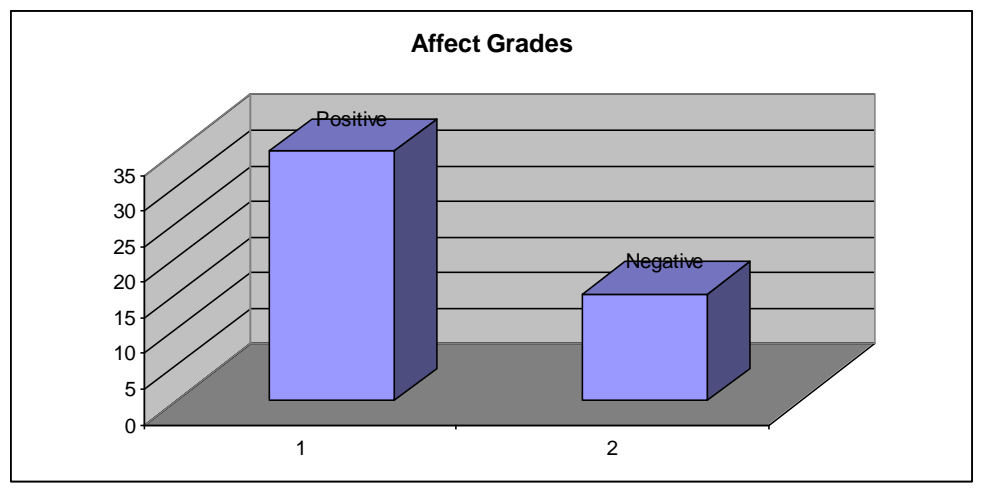

In a grade/marks conscious society, the flip side of any medium is realized when prolonged usage of the medium affects the academic performance of the students. Surprisingly, in this study majority 
say that Internet usage has affected grades positively, with a small number saying it does affect negatively.

\section{If you are prevented from using internet?}

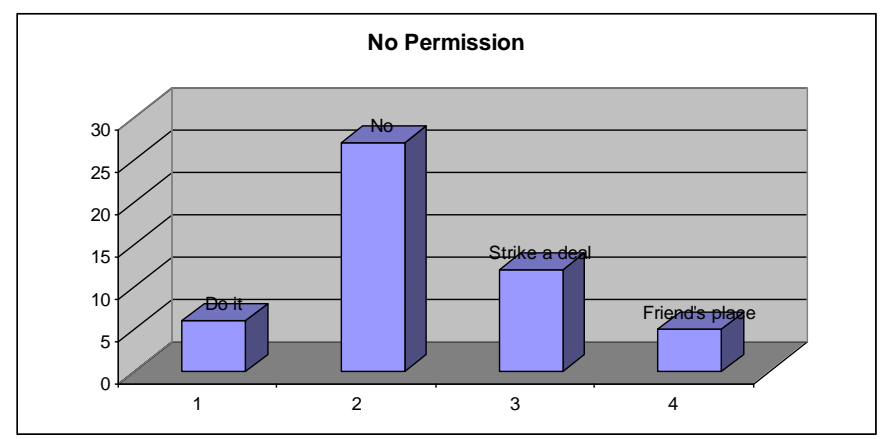

An ethical/moral angle was introduced in the study with this question - to find out as to whether students take the moral high ground or choose to be sly/wheeler dealers or abstain totally. As can be seen, a majority of the students remain ethical and say they will not use Internet at all if there is parental disapproval. This too does not come as a surprise since students rarely take the rebel route since the consequences can be extremely critical.

10. Have you ever been counseled about the good and bad things of internet usage?

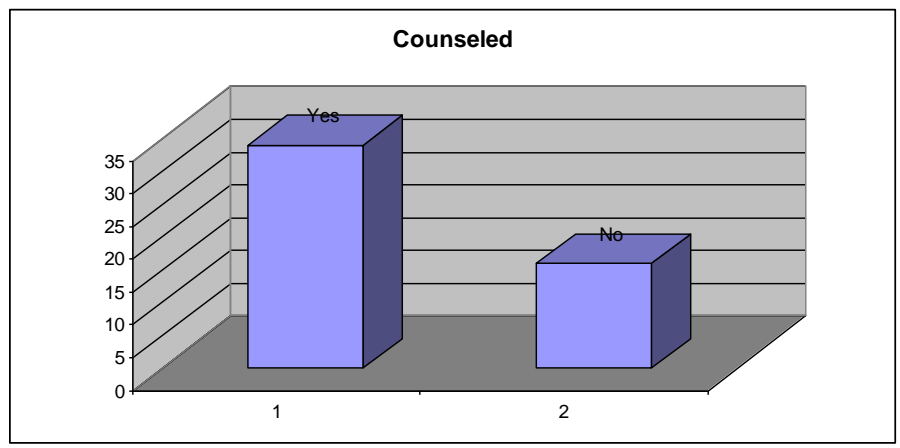

To the question on counseling, thirty students strongly say they have been counseled on the different facets of Internet. This shows that Internet usage is not an ad hoc activity but an informed well thought-out activity on the part of the students. A small number 
are not counseled with reference to the seamier side of the Internet which is not a positive trait especially where children are concerned. With regard to the threat to youngsters from bullies, sexual predators and other negative elements, parents are expected to talk to their children about such difficult issues; the absence of such a move by parents, a fact inferred through the responses from the respondents in this study, comes as a surprise.

\section{Who has counseled you?}

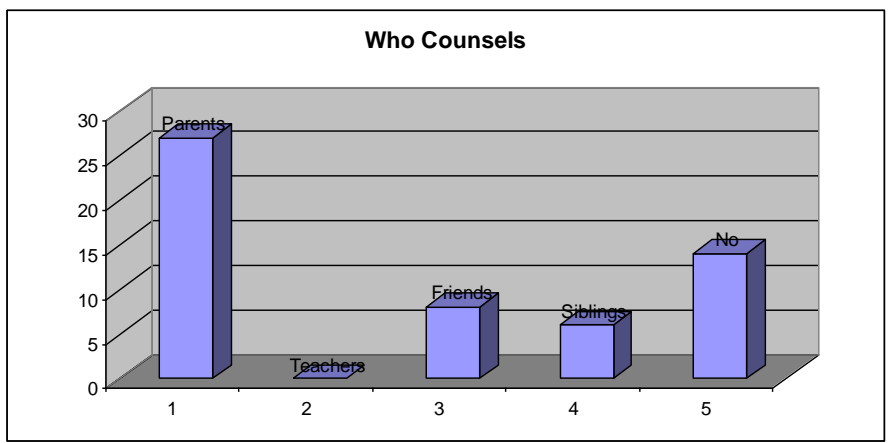

When it comes to children and Internet usage, the single most important factor is the involvement of parents. Parents are seen to be playing a major role in children's perception of Internet and the usage thereof. Friends and siblings have little or no role to play in influencing children's attitude towards Internet usage. There seems to be some kind of an anomaly here since the parents despite being a huge force in the lives of their children seem to be avoiding the obvious problem, which is to deal with uncomfortable issues. This may be understood as typical human nature that seeks to avoid confrontations.

\section{Experience with internet usage}

A major chunk of students mention their experience with Internet usage as being a good one, with a few remaining neutral in their appraisal. None report any nasty experiences or encounters during the course of Internet usage. 


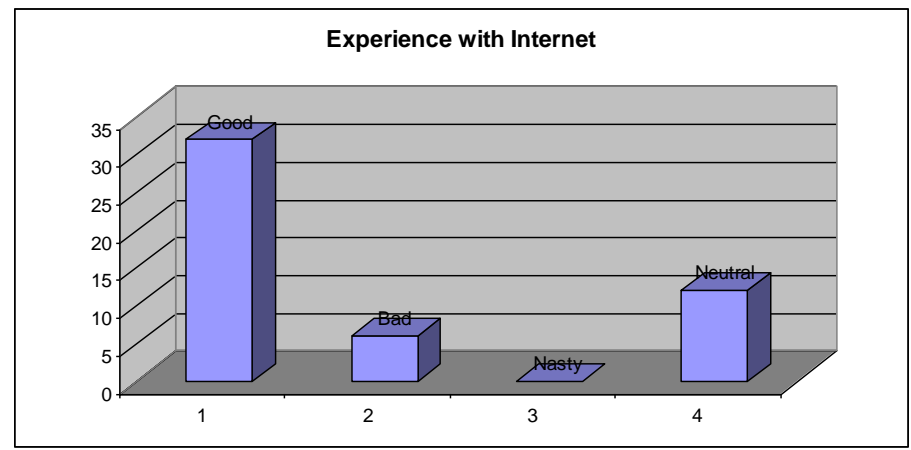

\section{Interview with Parents}

Of the three parents spoken to, all being mothers - reaction and responses are more or less similar and run along the expected lines. On the one hand they are proud about their children's tech savviness and ability to be part of the computer friendly world; they take pride in the fact that the kids use the Internet for accessing information, downloading the same as part of school work. They laud their kid's connectivity or presence in the social network scene. At the same time the parents lament at the sheer man hours the Internet seems to take away from the children. They agree that reading and playtime has been affected. Yet on given a suggestion to stop Internet usage by their children, they do not welcome the option. Only one of the three parents is aware of child-proof software as a protection against unwanted content on the Internet.

The general feeling that one gets from the parents is that they are more or less passive when it comes to problems or issues related to Internet usage and children. The worry and anxiety is more of an academic phenomenon to be dealt with by psychologists and researchers.

\section{Interview with Teachers}

The interviews with the teachers indicate that there is a consensus that more or less runs on accepted lines again. They disapprove too much of Internet but are not willing to quantify what is too much or too little, preferring to leave the responsibility to students and 
parents. They encourage students to work on projects sourced out from online content while being critical of the quality of the same. Teachers are condescending towards Internet content but expect students to be discerning users of Internet - which is an unrealistic expectation given the age and immaturity of the students. There are no guidelines given to children in schools by teachers as to what and how to go about using the Internet without losing out on one's credibility or creativity.

\section{Interpretation/Conclusion}

This study aims to get an added understanding of the effects of Internet on school children, which is the primary need of the day. With so much happening in the online space, we need to equip ourselves as parents, teachers, academicians and researchers regarding the nature of interaction between school children and new media. It clearly establishes a few facts that prove that the children are definitely taken in by Internet. However, unlike their western counterparts urban children in India are far more circumspect when it comes to using the internet. Out here in India, urban children are seen to increase the hours spent on the Internet as they grow older while younger kids seem to restrict their engagements with the internet to merely an hour as is clear from the data. Age clearly seems to be a strong factor in impacting internet usage. Further, the older they get they become enamored with things other than school work - social network, a primary cause of attraction - the effect of which is once again an issue for debate. As of now parents and teachers are not seen to be too proactive when it comes to handling the Internet's influence on children.

However, this study is too small in size and stature to get at conclusive pointers. It has merely tabled an agenda for future research.

There is much scope for longitudinal studies with a reckoning sample size across the country to get a clearer picture of how children's Internet usage seems to be changing their lives at every step of the way. India is ripe for proper media research along the lines of Andrea Press's 'Gender and social class identities in the 
new media environment' or Rebecca and Isac's 'Longitudinal study on internet effects'.

The internet certainly affords children needy access to creative means of information and content. Yet, children and their parents should be able to access external help and information that will allow the most extensive and creative use of internet resources.

\section{References}

Anderson, D. R., \& Evans, M. K. (2001). Perils and Potential of Media for Toddlers. Journal of American Psychological Association, 22(22), 10-16.

Calvert, S. L., \& Jordan, A. B. (2001). Children in the Digital Age. Journal of Applied Developmental Psychology, 22(1), 3-5.

Clay, R. A. (2005). Unraveling New Media's Effects on Children. Journal of American Psychology Association, 34(2), 40.

Hamelink, C. J. (2000). The ethics of cyberspace. London: Sage Publications.

Hemdev, M. (2007, August 23). Social Networking and Children: How Safe Are Indian Children on Social Networking Sites? Indian Child.

Küng, L., Picard, R. G., \& Towse, R. (2008). The internet and the mass media. London: Sage Publications.

Press, A. L., \& Alan, W. B. (2010). The New Media Environment: An Introduction. Chichester, West Sussex, U.K: Wiley-Blackwell.

Roberts, D. F., Rideout, V. J., Foehr, U. G., \& Brodie, M. (1999). Kids $\mathcal{E}$ media@ the new millennium. Menlo Park, CA: Henry J. Kaiser Family Foundation.

Saith, A., Vijayabaskar, M., \& Gayathri, V. (2008). ICTs and Indian social change: Diffusion, poverty, governance. Los Angeles: Sage Publications. 


\section{Questionnaire}

\section{New Media usage among School Children of Bangalore}

Please answer the following questions to the best of your ability. Please tick the options given, rank them where necessary- 1 being the highest. All the information provided will be in full confidence and will be used for research purpose only. Thank you for your cooperation.

1. Name:

2. Age:

3. School:

Std:

4. Male/Female:

5. Which is your most preferred medium? Rank them in the order of preference and usage:

Television

Radio

Books

Newspapers

Internet

6. How often do you use the internet in a day:

Less than 1 hour

1-2 hours

More than 2 hours

7. Why do you use the internet? Rank them in the order of usage:

School work

Information/General knowledge

Email/Chat

Social Networking

8. Is there adult supervision when using the internet:

Sometimes

Always

Never 
9. Has internet usage effected the following things:

Reading habit

TV viewing

Play time

10. Are your parents ok with you using the internet?

Yes

No

11. Do your teachers encourage you to use the internet for school work?

Yes

No

12. How has internet usage affected your grades?

Positively

Negatively

13. If you are prevented from using internet, will you do the following:

Do it anyway \& hope to get away with it

No, you will not

Strike a deal with parents and get your way

Not use at home but use at a friend's place

14. Have you ever been counseled about the good and bad things of internet usage:

Yes

No

15. Who has counseled you?

Parents

Teachers

Friends

Siblings

16. Your experience with internet usage has been:

Good

Bad

Nasty

Neutral 